\title{
Preprocessing and Facial Feature Robust to Illumination Variations
}

\author{
Dong-Ju Kim ${ }^{\dagger} \cdot$ Sang-Heon Lee ${ }^{\dagger} \cdot$ Hyun-DuK Kim ${ }^{+\dagger}$
}

\begin{abstract}
In this paper, we propose the face recognition method combining the ECSP preprocessing technique which is modified version of previous CS-LBP and the illumination-robust D2D-PCA feature. The performance evaluation of proposed method was carried out using various binary pattern operators and feature extraction algorithms such as well-known PCA and 2D-PCA on the Yale B database. As a results, the proposed method showed the best recognition accuracy compared to different approaches, and we confirmed that the proposed approach is robust to illumination variation.
\end{abstract}

Keywords : Face Recognition, Preprocessing, Illumination Variation

\section{조명변화에 강인한 전처리 및 얼굴특징}

김 동 주 $^{\dagger}$ 이 상 헌 ${ }^{\dagger}$ 김 현 덕 ${ }^{+\dagger}$

\begin{abstract}
요 약
본 논문에서는 기존의 CS-LBP를 변형한 ECSP 전처리 기법과 조명에 강인한 D2D-PCA 특징을 결합하는 얼굴인식 방법에 대하여 제안한 다. 제안하는 얼굴인식 방법의 성능평가는 Yale B 데이터베이스 상에서 기존의 다양한 이진패턴 변환 영상과 얼굴인식에 널리 사용되고 있는 $\mathrm{PCA}$ 및 2D-PCA 특징을 이용하여 수행되었다. 실험 결과, 제안하는 얼굴인식 방법은 다른 방법들에 비하여 가장 높은 인식 성능을 보였으며, 이로부터 제안 시스템이 조명 변화에 강인한 얼굴인식 방법임을 확인하였다.
\end{abstract}

키워드 : 얼굴인식, 이진패턴, 전처리, 조명변화

\section{1. 서 론}

최근, $\mathrm{LBP}(\mathrm{Local}$ Binary Pattern)[1]는 조명변화에 강인한 전처리 방법으로 얼굴인식 및 표정인식 분야에서 소개되어, CBP(Centerized Binary Pattern)[2] 및 CS-LBP(Center Symmetric Local Binary Pattern)[3] 등과 같은 다양한 형 태로 발전하였다. 이에, 본 논문에서는 기존의 이진패턴 변 환 방법을 기반으로 얼굴 영상의 텍스처 성분을 보다 잘 표 현할 수 있는 ECSP(Extended Center Symmetric Pattern) 을 고안하였으며, 이를 $\mathrm{D} 2 \mathrm{D}-\mathrm{PCA}$ (Differential TwoDimensional Principal Component Analysis)[4]와 결합하는 얼굴인식 시스템에 대하여 제안한다. $\mathrm{D} 2 \mathrm{D}-\mathrm{PCA}$ 는 조명변화 에 강인한 얼굴 특징을 표현하는 하나의 방법으로써, 이는

※ 본 연구는 문화체육관광부 및 한국콘텐츠진흥원의 2013년도 문화콘텐츠 산업기술 지원사업의 연구결과와 교육과학기술부에서 지원하는 대구경북 과학기술원 기관고유사업에 의해 수행되었음(13-IT-03).

† 정 회 원 : 대구경북과학기술원 IT융합연구부 선임연구원

†† 정 회 원: 대구경북과학기술원 IT융합연구부 연구원 논문접수: 2013년 2월 15일 심사완료: 2013 년 3 월 12 일

* Corresponding Author:Sang-Heon Lee(pobbylee@dgist.ac.kr) Hyun-Duk Kim(hyunduk00@dgist.ac.kr)
2D-PCA(Two-Dimensional Principal Component Analysis) [5] 행 벡터의 차이성분을 계산하여 얻어진다. 제안 방법의 성능 비교는 Yale B 공인 얼굴 데이터베이스 상에서 기존 의 $\mathrm{PCA}$ (Principal Component Analysis)[6]와 2D-PCA 알고 리즘을 이용하여 수행되었고, 실험으로부터 제안 방법이 조 명 변화에 강인한 얼굴인식 방법임을 확인하였다.

\section{2. 얼굴인식}

\section{1 전처리}

조명변화에 강인한 얼굴인식을 위하여 본 논문에서는 다 양한 이진패턴 연산을 이용하여 전처리를 수행하였다. 특히, 본 논문에서는 기존의 이진패턴 연산을 변형한 $\mathrm{ECSP}$ 연산 을 고안하여 적용함으로써, 성능 향상을 도모하였다. 일반적 으로, $\mathrm{LBP}$ 는 그레이 레벨의 각 화소값을 이용하여 에지, 점, 코너 등과 같은 얼굴의 로컬 텍스처 특징을 표현하는데 이 용된다. $\mathrm{LBP}$ 는 조명에 민감하지 않은 영상 변환의 한 방법 으로써, 수식 (1)과 같이 표현되며 현재 위치의 화소값과 이 웃 화소값의 차이를 0 과 1 의 값으로 나타낸다. 


$$
\operatorname{LBP}(P, R)=\sum_{p=0}^{P-1} s\left(g_{p}-g_{c}\right) 2^{p}, s(x)= \begin{cases}1 & x \geq 0 \\ 0 & x<0\end{cases}
$$

수식 (1)에서 $P$ 와 $R$ 은 각각 인접 화소의 수와 원의 반 지름을 의미하며, $g_{c}$ 와 $g_{p}$ 는 중심화소의 화소값 및 이웃화 소의 화소값을 각각 의미한다. Fig. 1은 임의의 영상블록에 대한 화소의 위치와 LBP 패턴 생성 방향을 도시하고 있다.

\begin{tabular}{|c|c|c|}
\hline$g_{0}$ & $g_{1}$ & $g_{2}$ \\
\hdashline$g_{7 \uparrow}$ & $g_{c}$ & $g_{3}$ \\
\hline$g_{6}$ & $g_{5}$ & $g_{4}$ \\
\hline
\end{tabular}

Fig. 1. LBP operator in $3 \times 3$ block

더불어, 얼굴 및 표정인식을 위하여, 최근, $\mathrm{CBP}$ 및 $\mathrm{CS}-\mathrm{LBP}$ 와 같은 이진패턴이 제안되었다. $\mathrm{LPB}$ 가 중심화소와 각각의 이웃화소들을 비교하는 것과는 달리, $\mathrm{CBP}$ 는 중심화 소의 영향을 고려한 이진패턴 변환 방법이다. $\mathrm{CBP}$ 는 중심 화소를 중심으로 대칭하고 있는 이웃화소들을 각각 비교하 고, 전체화소의 평균값 $g_{T}$ 와 중심화소 $g_{c}$ 를 비교하여 이진 패턴을 생성하는 방법으로, 수식 (2)와 같이 표현된다.

$$
\begin{aligned}
C B P(P, R)= & \sum_{p=0}^{(P / 2)-1} s\left(g_{p}-g_{p+(P / 2)}\right) 2^{p}+ \\
& s\left(g_{c}-\frac{1}{P+1}\left(\sum_{p=0}^{P-1} g_{p}+g_{c}\right)\right) 2^{P / 2}, \\
& s(x)= \begin{cases}1 & x \geq 0 \\
0 & x<0\end{cases}
\end{aligned}
$$

$\mathrm{CS}-\mathrm{LBP}$ 는 $\mathrm{CBP}$ 에서 중심화소와 평균값의 비교 과정을 수행하지 않고, 중심화소를 기준으로 대칭되는 이웃화소들 과의 비교만을 수행하는 $\mathrm{CBP}$ 의 변형된 방법으로 수식 (3) 과 같이 계산된다.

$$
\begin{gathered}
C S-L B P(P, R)=\sum_{p=0}^{(P / 2)-1} s\left(g_{p}-g_{p+(P / 2)}\right) 2^{p}, \\
s(x)= \begin{cases}1 & x \geq 0 \\
0 & x<0\end{cases}
\end{gathered}
$$

기존 연구를 바탕으로, 본 논문에서는 얼굴의 텍스처 성 분을 더 잘 표현하는 $\mathrm{ECSP}$ 변환 방법을 고안하였다. $\mathrm{ECSP}$ 는 기존의 $\mathrm{CS}-\mathrm{LBP}$ 의 변형된 형태로, 중심화소를 기준으로 대칭되는 주변화소 값들을 비교하는 방식은 $\mathrm{CS}-\mathrm{LBP}$ 와 동 일하나, 이진패턴을 생성하는 과정에서 가중치를 다르게 하 여 패턴을 구성한다는 특징을 갖는다. 일반적으로, 얼굴의 텍스처는 수직 또는 수평 방향의 성분보다는 대각 방향의
성분이 보다 더 중요한 정보를 포함한다. 이에, $\mathrm{ECSP}$ 는 이 진패턴을 생성하는 과정에서 대각으로 대칭되는 성분에 중 요도를 높게 부여하여 얼굴의 텍스처를 생성하며, 수식 (4) 로 계산된다.

$$
\begin{gathered}
\operatorname{ECSP}(P, R)=\sum_{p=0}^{(P / 2)-1} s\left(g_{p}-g_{p+(P / 2)}\right) 2^{w_{P, R}(p)}, \\
s(x)= \begin{cases}1 & x \geq 0 \\
0 & x<0\end{cases}
\end{gathered}
$$

수식 (4)에서 $w_{P, R}(p)$ 는 이진패턴 생성과정에서 비트 가 중치를 결정하는 함수를 의미하며, $P$ 와 $R$ 이 8 과 1 일 경우, $w(p)$ 는 수식 (5)로 정의된다.

$$
w(p)=(3,1,2,0), p=0,1,2,3
$$

Fig. 2는 기존의 다양한 이진패턴 연산을 이용한 변환 영 상과 $\mathrm{ECSP}$ 변환 영상의 예시를 보이고 있다. Fig. 2로부터 $\mathrm{ECSP}$ 영상은 $\mathrm{LBP}, \mathrm{CBP}$ 및 $\mathrm{CS}-\mathrm{LBP}$ 영상보다 텍스처 성 분이 보다 더 현저하게 표현되고 있음을 알 수 있다.

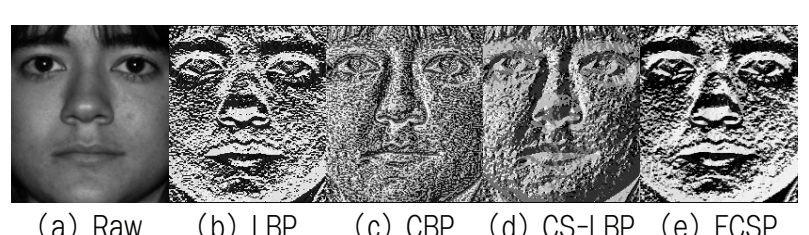

(a) Raw

(b) LBP

(c) CBP

(d) CS-LBP (e) ECSP

Fig. 2. Sample images by various binary patterns

\section{2 특징추출 및 인식}

본 논문에서는 조명변화에 강인한 특징추출을 위하여 $\mathrm{D} 2 \mathrm{D}-\mathrm{PCA}$ 를 사용하였다[4]. D2D-PCA는 2D-PCA가 linebased 특징 매트릭스인 점에 착안하여 특징 행 벡터 사이의 차이 성분을 이용한 것으로, 특징 행 벡터 사이의 차이 성분이 조명변화에 보다 강인하다는 가정에 기반한다. 즉, $\mathrm{D} 2 \mathrm{D}-\mathrm{PCA}$ 는 $2 \mathrm{D}-\mathrm{PCA}$ 특징벡터를 생성하고, 이들의 차이 성분을 계산하 여 얻어진다. 먼저, $2 \mathrm{D}-\mathrm{PCA}$ 는 다음과 같은 과정으로 계산된 다. 얼굴영상 크기가 $m \times n$ 인 이미지 행렬을 $A$ 라 하고, 행들 이 서로 정규직교하는 행렬을 $X \in R^{n \times d}, n \geq d$ 라 하자. 이미 지 행렬 $A$ 가 $X$ 축에 투영된다면, $m \times d$ 의 행렬은 $Y=A X$ 로 계산된다. 이때, $2 \mathrm{D}-\mathrm{PCA}$ 는 최적의 투영 행렬 $X$ 를 결정하는데, 이미지 행렬 샘플의 분산을 사용한다. $N$ 개의 학습 영상 샘플을 $A_{k}(k=1,2, \cdot \cdot \cdot, N)$ 라 하고, 학습 샘 플들의 평균이미지를 $\bar{A}=N \sum_{k} A_{k}$ 라 하자. 학습 얼굴 영상들 의 이미지 공분산 행렬 $G$ 는 수식 (6)으로 계산된다.

$$
G=\frac{1}{N} \sum_{k=1}^{N}\left(A_{k}-\bar{A}\right)^{T}\left(A_{k}-\bar{A}\right)
$$


이때, 최적의 투영 행렬 $X_{o p t}$ 는 최대 고유치를 갖는 공분 산 행렬 $G$ 의 $d$ 개의 고유벡터 $X_{1}, X_{2}, \cdots \cdot, X_{d}$ 로 구성된 다. 공분산 행렬 $G$ 는 단지 $n \times n$ 의 크기를 가지므로 고유 벡터 $X_{o p t}$ 는 매우 효율적으로 계산될 수 있다. 고유벡터 $X$ 는 $n \times d$ 차원의 행렬이므로, 주어진 얼굴 영상 $A(m \times n)$ 의 $2 \mathrm{D}-\mathrm{PCA}$ 특징벡터 $Y_{k}(m \times d)$ 는 수식 (7)과 같이 고유벡 터의 축에 투영함으로써 계산된다.

$$
Y_{k}=(A-\bar{A}) X_{k}, k=1,2, \cdots, d
$$

다음으로, $\mathrm{D} 2 \mathrm{D}-\mathrm{PCA}$ 특징은 간단하게 $2 \mathrm{D}-\mathrm{PCA}$ 특징으로 부터 얻어진다. $2 \mathrm{D}-\mathrm{PCA}$ 는 $m$ 개의 행과 $d$ 의 열로 이루어진 벡터이므로 $\mathrm{D} 2 \mathrm{D}-\mathrm{PCA}$ 는 수식 (8)과 같이 각 행벡터 사이의 차이를 계산함으로써 얻어진다. 여기서 $y_{i}$ 는 $i$ 번째 행의 $2 \mathrm{D}-\mathrm{PCA}$ 행 벡터를 의미하며, $d y$ 는 $\mathrm{D} 2 \mathrm{D}-\mathrm{PCA}$ 특징벡터를 의미한다.

$$
\begin{aligned}
& d y_{i, j}=y_{i+1, j}-y_{i, j}, \\
& i=1,2, \cdots, m-1, j=1,2, \cdots, d .
\end{aligned}
$$

위와 같은 과정으로 추출된 $\mathrm{D} 2 \mathrm{D}-\mathrm{PCA}$ 특징은 2 차원 행 렬 형태로 구성되며, 유클리디언 거리 기반의 최근접 이웃 분류기를 통하여 얼굴 인식은 수행된다.

\section{3. 실험 및 결과}

제안하는 얼굴 인식 방법이 조명변화 환경에 강인하고 효 율적 인지의 여부를 평가하기 위하여, 본 논문에서는 Yale $\mathrm{B}$ 공인 얼굴 데이터베이스를 성능평가에 사용하였다[7]. Yale B 얼굴 데이터베이스는 다양한 포즈와 조명 변화 환 경에서 얼굴인식 알고리즘의 성능평가를 위해 구축된 공인 데이터베이스로써, 본 논문에서는 38 명의 사람에 대한 정면 포즈의 64개 조명변화 환경에서 구축된 2,432장의 영상을 실 험에 사용하였다. 더불어, 얼굴 인식 성능 평가는 Fig. 3에 도시한 바와 같이 조명 변화가 거의 없는 5 장의 영상을 학 습에 사용하였고, 나머지 영상을 테스트에 사용하였다.
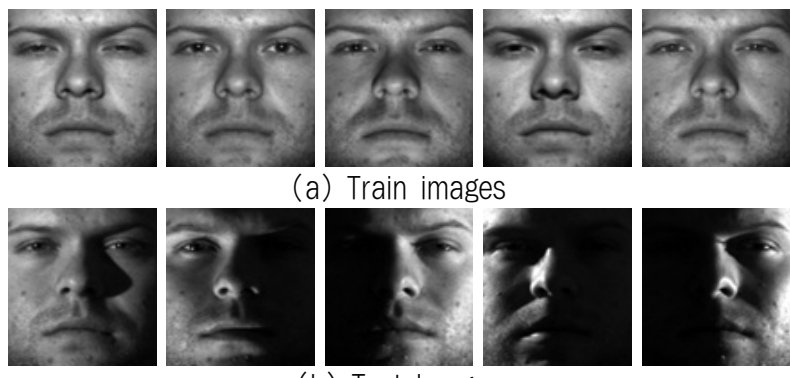

(b) Test Images

Fig. 3. Sample images of the Yale B database
얼굴인식 실험은 원본영상, $\mathrm{LBP}, \mathrm{CBP}, \mathrm{CS}-\mathrm{LBP}$ 및 $\mathrm{ECSP}$ 전처리 영상들과 $\mathrm{PCA}, 2 \mathrm{D}-\mathrm{PCA}$ 및 $\mathrm{D} 2 \mathrm{D}-\mathrm{PCA}$ 알고 리즘을 이용하여 수행되었다. 실험결과, $\mathrm{PCA}, 2 \mathrm{D}-\mathrm{PCA}$ 및 $\mathrm{D} 2 \mathrm{D}-\mathrm{PCA}$ 를 사용한 특징차원에 따른 인식 결과를 Fig. 4, Fig. 5, Fig. 6에 각각 나타내었으며, Table 1에 성능평가 결 과를 요약하였다. 실험으로부터 $\mathrm{ECSP}$ 영상과 $\mathrm{D} 2 \mathrm{D}-\mathrm{PCA}$ 를 결합한 제안 방법은 $98.26 \%$ 의 가장 높은 인식률을 보였다. 더불어, 다양한 전처리 영상을 고려하여 성능을 비교하였을 경우, 모든 알고리즘에 대하여 $\mathrm{ECSP}$ 영상을 사용하였을 때 가장 좋은 성능을 보였으며, 이로부터 제안하는 이진패턴 변환 방법의 효용성을 확인할 수 있었다. 또한 알고리즘에 따른 인식 성능을 비교하였을 경우, $\mathrm{D} 2 \mathrm{D}-\mathrm{PCA}$ 특징이 조명 에 가장 강인한 특징추출 방법임을 확인할 수 있었다. 결론 적으로, 본 논문에서는 조명변화에 강인한 전처리 방법과 특징 추출에 대한 연구를 수행하였고, 실험결과, 제안 방법 의 효용성을 확인할 수 있었다.

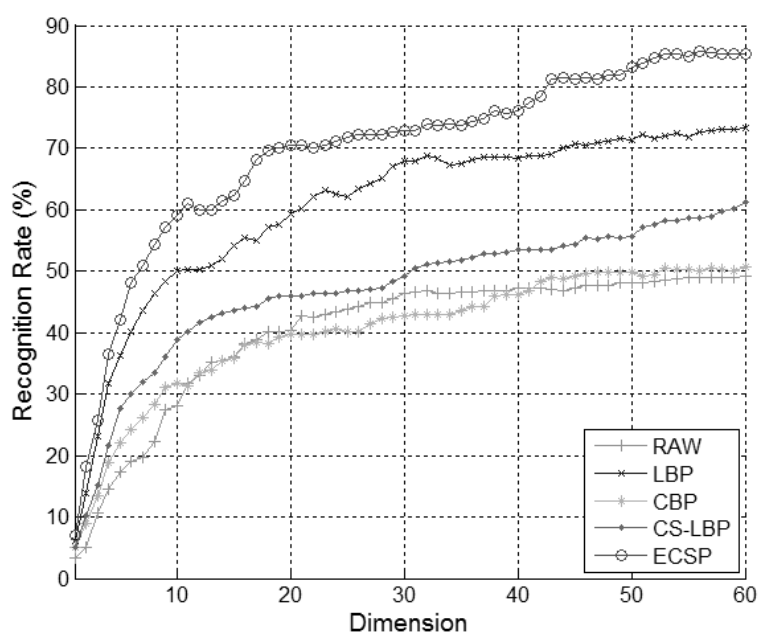

Fig. 4. Recognition results by PCA

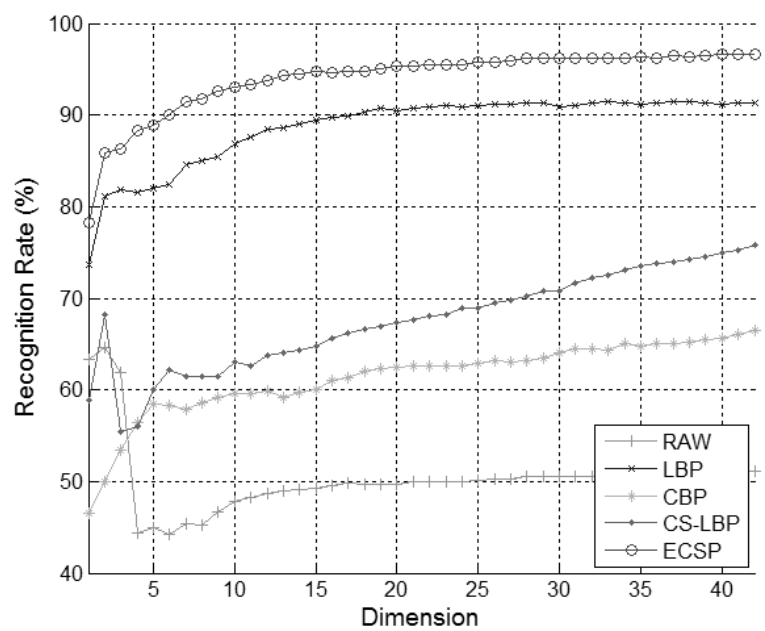

Fig. 5. Recognition results by 2D-PCA 


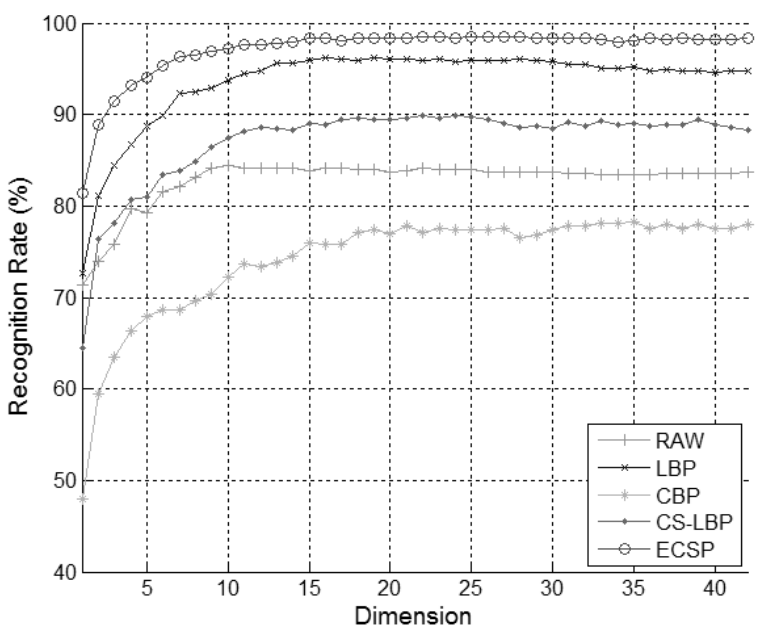

Fig. 6. Recognition results by D2D-PCA

Table 1. Summary of maximum recognition rates

\begin{tabular}{cccc}
\hline & PCA & 2D-PCA & D2D-PCA \\
\cline { 2 - 4 } Raw & $49.11 \%$ & $64.58 \%$ & $84.43 \%$ \\
LBP & $73.24 \%$ & $91.46 \%$ & $95.88 \%$ \\
CBP & $50.67 \%$ & $66.55 \%$ & $78.28 \%$ \\
CS-LBP & $61.33 \%$ & $75.81 \%$ & $89.93 \%$ \\
ECSP & $85.86 \%$ & $96.37 \%$ & $98.26 \%$ \\
\hline
\end{tabular}

\section{4. 결 론}

조명 변화에 강인한 얼굴인식을 위하여, 본 논문에서는 $\mathrm{ECSP}$ 전처리 기법과 $\mathrm{D} 2 \mathrm{D}-\mathrm{PCA}$ 특징추출 기법에 대하여 제안하였다. Yale B 얼굴 데이터베이스에서 기존의 다양한 이진패턴 영상과 $\mathrm{PCA}, 2 \mathrm{D}-\mathrm{PCA}$ 등의 알고리즘을 이용하여 제안방법의 성능평가를 수행한 결과, $\mathrm{ECSP}$ 영상과 $\mathrm{D} 2 \mathrm{D}-$ $\mathrm{PCA}$ 를 결합한 제안방법이 $98.26 \%$ 의 가장 높은 인식률을 보였다. 이로부터 본 논문의 제안방법이 조명변화에 강인한 효과적인 얼굴인식 방법임을 확인하였다.

\section{참 고 문 헌}

[1] T. Ahonen, A. Hadid, and M. Pietikainen, "Face Description with Local Binary Patterns: Application to Face Recognition," IEEE Transaction on Pattern Analysis and Machine Intelligence, Vol.28, No.12, pp.2037-2041, 2006.

[2] X. Fu, and W. Wei, "Centralized Binary Patterns Embedded with Image Euclidean Distance for Facial Expression Recognition," International Conference of Neural Computation, pp.115-119, 2008.

[3] H. Marko, P. Matti, and S. Cordelia, "Description of Interest Regions with Center-Symmetric Local Binary Patterns," Indian Conference on Computer Vision, Graphics and Image Processing, pp.58-69, 2006.
[4] Sang-Heon Lee, Dong-Ju Kim and Jin-Ho Cho, "Illumination-robust face recognition system based on differential components", IEEE Transactions on Consumer Electronics, Vol.58, No.3, pp.963-970, 2012.

[5] Y. Jian, Z. David, F. Alejandro, and J.Y. Yang, "Twodimensional PCA: A New Approach to Appearance-based Face Representation and Recognition," IEEE Transactions on Pattern Analysis and Machine Intelligence, Vol.26, No.1, pp.131-137, 2004.

[6] M. Turk and A. Pentland, "Eigenfaces for recognition", Journal of Cognitive Neurosci, Vol.3, No.1, pp.71-86, 1991.

[7] A. Georghiades, P. Belhumeur, and D. Kriegman, "From few to many: Illumination Cone Models for Face Recognition under Variable Lighting and Pose," IEEE Transactions on Pattern Analysis and Machine Intelligence, Vol.23, No.6, pp.643-660, 2001.

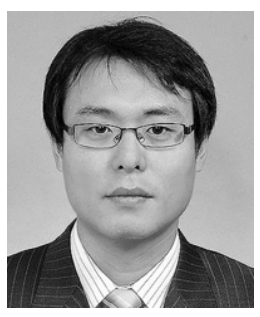

\section{김 동 주}

e-mail : radioguy@dgist.ac.kr 1998년 충북대학교 전파공학과(학사) 2000년 충북대학교 전파공학과(석사) 2010년 성균관대학교 정보통신공학부(박사) 2011년 현 재 대구경북과학기술원 IT융합연구부 선임연구원 관심분야: 얼굴인식, $\mathrm{HCI}$, 영상신호처리, 패턴인식

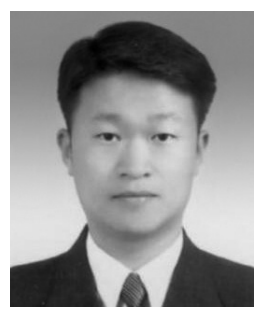

이 상 헌 e-mail : pobbylee@dgist.ac.kr 1993년 경북대학교 전자공학과(학사) 1996년 경북대학교 전자공학과(석사) 2013년 경북대학교 전기전자공학과(박사) 2005년 현 재 대구경북과학기술원 IT융합연구부 선임연구원 관심분야: 컴퓨터비전, 영상신호처리

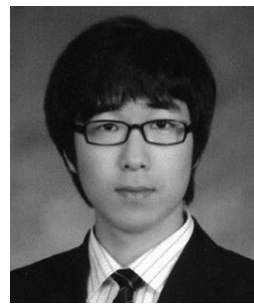

\section{김 현 덕}

e-mail : hyunduk00@dgist.ac.kr 2009년 경북대학교 수학과(학사) 2012년 경북대학교 수학과(석사) 2012년 현 재 대구경북과학기술원 IT융합연구부 연구원 관심분야: 초해상도 영상복원, 컴퓨터비전 